\title{
Paris, capital editorial do mundo lusófono na primeira metade do século XIX?*
}

\author{
Paris, editorial capital of the Luso-Brazilian \\ book world in the first halph of XIXth centuries? ${ }^{* *}$
}

\section{Paris, capitale éditoriale du monde lusophone dans la première moitié du XIXe siècle?}

\author{
DIANA COOPER-RICHET \\ Centre d'Histoire Culturelle des Sociétés Contemporaines \\ Université de Versailles Saint-Quentin-en-Yvelines Universidade de Versailles \\ 47, Boulevard Vauban. 78047 Guyancourt Cedexrance \\ Saint-Quentin-en-Yvelines. France \\ iana.cooper-richet@admin.uvsq.fr; diana.cooper-richet@uvsq.fr
}

RESUMO Este artigo analisa a produção e circulação de livros, revistas e periódicos em português na e a partir de Paris na França, onde eram produzidos e de onde eram exportados. Analisa sua tipologia, a extensão

* Artigo recebido em: 09/04/2009. Aprovado em: 14/06/2009.

** Tradução de Clara Furtado Lins. 
dessa produção, os livreiros responsáveis e o impacto desses impressos, tanto na França quanto no mundo lusófono.

Palavras chave livros, edição, impressos, lusófonos

ABSTRACT This article analyses the production and circulation of books, journals and reviews written in Luso-Brazilian and printed in Paris - France. From there it was commercialized and exported. Discuss the typology of this printing material, the production number, who were the editors and the impact of these printing material in the Luzo-Brazilian world.

Keyword books, edition, printing, Luzo-Brazilian

\section{Introdução}

Ao longo do século XIX, Paris foi considerada a capital mundial das artes e das letras, uma cidade de tropismo incomparável, atraindo habitantes de todos os países. Mas, o que é menos conhecido é que esta cidade também desempenhou um papel importante na produção e circulação de impressos em várias línguas. O que chamamos de "livrarias estrangeiras" na França dessa época, é um setor particular do mundo dos livros onde editores-livreiros produziram e venderam materiais impressos em diversas línguas estrangeiras, ${ }^{1}$ das mais raras - conhecidas hoje como periféricas - às mais difundidas, indo do mongol ou persa ao inglês, passando pelo copta, o italiano, mas também o português, e isto, desde os primeiros anos após a Revolução.

Essas produções eram dirigidas a diferentes públicos: os especialistas e eruditos, já que se trata de línguas raras faladas em regiões distantes da França, mas também os visitantes e residentes estrangeiros. Os ingleses, por exemplo, cada vez mais numerosos em estadas no continente, estavam à

1 Ver sobre esse tema COOPER-RICHET, Diana. Paris, capitale des polyglottes? Edition et commercialisation des imprimés en langues étrangères sous la Restauration. In : MOLLIER, Jean-Yves, REID, Martine et YON, JeanClaude. (éd.) Repenser la Restauration. Paris : Nouveau Monde, 2005, p.197-209; COOPER-RICHET, Diana. Presse en anglais et littérature, à Paris, dans la première moitié du XIX siècle. In : THERENTY, Marie-Eve et VAILLANT, Alain. (dir.) Presse et plumes: journalisme et littérature au XIX siècle. Paris : Nouveau Monde, 2004, p.153-168; COOPER-RICHET, Diana. Les imprimés de langue anglaise en France au XIX ${ }^{\circ}$ siècle: rayonnement intellectuel, circulation et modes de pénétration. In : MOLLIER, J.Y. et MICHON, Jacques. (dir.) Les mutations du livre et de l'édition dans le monde du XVIII' siècle à I'an 2000. Québec/Paris: Presses de I'Université Laval/L'Harmattan, 2001, p.122-140; COOPER-RICHET, Diana. L'imprimé en langues étrangères à Paris au XIX siècle: lecteurs, éditeurs, supports. Revue française d'histoire du livre, n.116 et 117, p.203-325, $3^{\circ}$ et $4^{\circ}$ trimestres 2002 (paru en octobre 2003); COOPER-RICHET, Diana. La librairie étrangère à Paris au XIX siècle: un milieu perméable aux innovations et aux transferts. Actes de la Recherche en Sciences Sociales, n.126-127, p.60-69, mars 1999; COOPER-RICHET, Diana. Paris et l'écoute des cultures du monde au XIX siècle. Les Cahiers du XIX ${ }^{\circ}$ siècle, n.3, p.223-243, 2008; COOPER-RICHET, Diana. Diffusion du modèle victorien à travers le monde. Le rôle de la presse en anglais publiée en France au XIX ${ }^{\circ}$ siècle. Colloque international Presse, identités nationales et transferts culturels au XIX $X^{\circ}$ siècle. Montpellier, 17-19 mai 2006, à paraître en 2009; COOPER-RICHET, Diana. La presse britannique dans le Paris de la première moitié du XIX siècle: modèle et vecteur de transferts culturels. In: MOLLIER, Jean-Yves; REGNIER, Philippe e VAILLANT, Alain. (dir.) La production de l'immatériel. Théories, représentations et pratiques de la culture au XIX` siècle. Saint-Etienne: Publications de l'Université de Saint-Etienne, 2008, p.115-129. 
procura de livros e jornais em sua língua. O mesmo se aplica aos impressos em espanhol, especialmente na segunda metade do século, assim que os latino-americanos ${ }^{2}$ começam a desembarcar em maior número na Europa. Finalmente, os mercados abrem-se no Novo Mundo, especialmente na América do Sul, onde profissionais franceses investem, primeiro publicando livros que são exportados para diversos países do continente e, em seguida, se estabelecendo e abrindo livrarias.

No início do século XIX, o mundo lusófono vive uma profunda mudança. Em Portugal, a guerra contra Napoleão I e depois, em 1807, a partida da Família Real de Bragança para a sua colônia do outro lado do Atlântico. No Brasil, a luta a favor e, em seguida, a independência em 1822, acompanhada por uma modernização política e o surgimento de elites cultas e progressistas, ávidas de leitura. No entanto, os mercados portugueses e brasileiros ainda estavam longe de cobrir suas necessidades de impressos. Na segunda metade do século, algumas casas, como a Garnier, ${ }^{3}$ estabelecem-se no Brasil, para ali desenvolverem uma verdadeira indústria editorial local. Para todos esses leitores de origens diversas, Paris está, nas primeiras décadas do século XIX, na encruzilhada de todas as línguas e todas as culturas. Foi por essa razão que livros e periódicos em português serão ali publicados e vendidos.

A importância do papel desempenhado pela capital francesa na produção e circulação de impressos lusófonos em todo o mundo foi largamente subestimada até agora. Dois grupos de homens muito diferentes trabalharam nisso: o primeiro é composto por livreiros-editores-impressores franceses; o segundo, por homens de letras e ciências, tradutores, diretores de periódicos e artistas, tanto portugueses, quanto brasileiros, estabelecidos na França. Juntos, eles ajudaram a tornar a cidade um pólo de difusão da cultura e da língua portuguesa e brasileira. Nesta área, seria Paris capaz de competir com Lisboa, Coimbra ou Londres? Atualmente é possível produzir um primeiro quadro da produção editorial parisiense em português na primeira metade do século XIX, tanto do ponto de vista das obras e dos periódicos, bem como dos homens que a produziram.

\section{Livreiros-editores parisienses e o livro em português}

Graças ao trabalho pioneiro de contagem da Bibliografia da França, realizada por Victor Ramos, ${ }^{4}$ no final dos anos 1960 e início dos anos 1970,

2 Essa questao será tema da comunicaçao entre Diana Cooper-Richet e Michel Pierssens, intitulada Bohemia Latina au colloque international Bohème sans frontière/Bohemia without borders, Université de Toronto, 11-13 décembre 2008, a aparecer nas Editions de l'Université de Rennes em 2010.

3 Ver DUTRA, Eliana Regina de Freitas. Rebeldes literários da República: História e identidade nacional no Almanaque brasileiro Garnier (1903-1914). Belo Horizonte: Editora UFMG, 2005.

4 RAMOS, Victor. A edição em França: 1800-1850, repertório geral dos títulos publicados e ensaio crítico. Paris: Fundaçào Calouste Gulbenkian, 1972. 
sabemos hoje que, em Paris, entre 1797 e 1850, foram publicados cerca de 563 títulos em português, configurando uma média de 30 títulos por ano. É, naturalmente, durante as décadas 1820 e 1830, aquelas de maior agitação política no mundo lusófono, que a produção de livros é mais significativa. Ela passa de 2 a 3 livros nos primeiros anos deste período, para 41, em 1836, voltando a cair para somente 1, em 1855. Estão incluídos nesta contagem os catálogos de livros publicados em português por livreiros parisienses, assim como os dicionários e léxicos multilíngües, mas também obras em francês sobre a literatura ou a poesia portuguesa, não sendo estes últimos propriamente chamados livros lusófonos. Mas, é necessário adicionar a esta produção o conjunto de livros em português presente nas lojas da capital, assim como o material impresso disponível nos gabinetes de leitura, o qual Victor Ramos não considerou.

\section{Os profissionais franceses}

Certo número de profissionais franceses - livreiros-editores-impressores - investiu na divulgação dos impressos em português, tanto por motivos comerciais, como também intelectuais e de abertura para as culturas do mundo, apesar do incipiente estágio inicial desse mercado. Algumas casas foram muito ativas na área da "biblioteca lusófona", como aquela que JeanPierre Aillaud ${ }^{5}$ dirigiu. Como outros livreiros franceses - Rolland, ${ }^{6}$ Villeneuve, ${ }^{7}$ Bossange, Plancher, ${ }^{8}$ Didot, Garnier, ${ }^{9}$ de Mongie $^{10}$-, ele se mudou para o Rio de Janeiro, onde se associou a Hector Bossange. Em abril de 1827, os

5 Jean-Pierre (Joao Pedro) Aillaud, nascido em 1752, em Monestier de Briançon, se instalou em Coimbra em 1770, onde abriu uma livraria, depois se associando a Bertrand. Ele era pai de três filhos, um seu homônimo, Jean-Pierre, que foi livreiro em Paris. Ver: HALLEWELL, Laurence. Livros no Brasil: sua história. São Paulo: Edusp, 2005, p.198, 232, 289, 291; GUEDES, Fernando. O livro e a leitura em Portugal: subsídios para a sua história - séculos XVIIIXIX. Lisboa: Verbo, 1987, p.42 e LOUREIRO, Joao Pinto. Livreiros e Livrarias de Coimbra. Arquivo Coimbrão, n.12, p.69-171, 1954. A viúva de Bertrand e seus filhos, livreiros em Lisboa, publicaram em 1835 um catálogo de 15 páginas dedicado às obras em português, do qual a BNF conserva um exemplar, ver sobre o tema os trabalhos de DOMINGOS, Manuela D. Bertrand, une librairie avant le tremblement de terre. Lisbonne: Biblioteca Nacional, 2002.

6 Ver: HALLEWELL, Laurence. Livros no Brasil: sua história, p.102.

7 Ver: HALLEWELL, Laurence. Livros no Brasil: sua história, p.120, 122, 148, 150, 154.

8 Ver: HALLEWELL, Laurence. Livros no Brasil: sua história, p.139, 142, e 150. Chegou ao Rio de Janeiro em torno de 1824, para servir no Exército imperial. Ali foi notável editor do Jornal de Commercio. Voltará à França em 1844.

9 Um de seus irmãos, Baptiste Louis, presente desde 1844, será o verdadeiro inventor da literatura nacional. Foi ele, o primeiro que decidiu remunerar os escritores lusófonos que, até então, publicavam por sua própria conta. Proprietário da maior estrutura no Rio de Janeiro, ele será verdadeiramente o arquétipo do editor brasileiro moderno. MOLLIER, Jean-Yves. La construction du système éditorial français et son expansion dans le monde du XVIII' au XXe siècle. In: Les mutations du livre et de l'édition dans le monde du XVIII' à l'an 2000. Paris/Québec: L'Harmattan/Presses de I'Université Laval, 2001, p.62. Os irmãos Garnier foram também provedores de livros obscenos para toda a América Latina, ver: MOLLIER, Jean-Yves. L'argent et les lettres: Histoire du capitalisme d'édition (1880-1920). Paris: Fayard, p.239 et HALLEWELL, Laurence. Livros no Brasil: sua história, p.211.

10 Ver SCHAPOCHNIK, Nelson. Maudits typographes. Cahiers du Brésil contemporain - Cheminements du roman dans le Brésil du XIX ${ }^{\circ}$ siècle, dir. Sandra Guardini Teixeira Vasconcelos, n.69/70, 2008, p.117; HALLEWELL, Laurence. Livros no Brasil: sua história, p.197-201 e 209-211. Mongie, instalado, como a maior parte de seus colegas franceses, na rua do Ouvidor, não possuía uma livraria independente, mas somente uma filial da maison parisiense do mesmo nome. 
dois abriram uma loja cujo razão social era Souza et Laëmmert et cie, para qual Hector Bossange enviava livros em francês. ${ }^{11}$

O papel de Jean-Pierre Aillaud para as transferências culturais entre a França e o Brasil resta ainda a ser avaliado. É, no entanto, o livreiro parisiense que mais investiu na área lusófona. Com 52 livros em português publicados durante a primeira metade do século XIX, ele ocupa o primeiro lugar dos que se dedicaram a esse ramo editorial. Os catálogos da sua casa, conservados na Bibliothèque Nationale de France (BNF), testemunham o interesse que atribui à linguagem e à cultura portuguesa. Em 1820, o Supplément au Catalogue de la Librairie Etrangère et Française de Jean-Pierre Aillaud, com uma dezena de páginas, dedica metade às obras nessa língua. Onze anos mais tarde, em 1832, o Catalogue général de fonds, d'assortiment et en commission, que então consta de 66 páginas, apresenta em 2 delas, 30 títulos em português. Em junho de 1835, o estabelecimento, que agora ostenta o nome de "Livraria diplomática, francesa e estrangeira Aillaud JeanPierre", propõe, nas 30 páginas de seu catálogo, 3 de livros em português, com preços fixos e grandes descontos.

Porém, é na década de 1840, que Aillaud dá ênfase a este segmento específico do mercado do livro. O Catalogue à un rabais extraordinaire (Catálogo com um desconto extraordinário), de setembro de 1842, contém as seguintes seções: "Livros Portugueses" (4 p.), "Livros publicados pela Academia Real de Ciências de Lisboa" (2 p.), "Livros de Sylvestre Pinheiro Ferreira" (2 p.) e "Livros clássicos adotados nas escolas de Portugal e do Brasil" (2 p.), que mostram o crescimento do acervo lusófono nesta livraria. Dois anos mais tarde, o Catalogo dos livros portuguezes e latinos publicados em Pariz par Jean-Pierre Aillaud continha 20 páginas e, em 1846, apresenta 12 a mais. Desta vez, os títulos são classificados como "Livros de Fundos" (14 p.), "Livros Latinos adotados para as aulas de Portugal e do Brasil. Impressos em Pariz" (2 p.), depois "Livros portuguezes publicados em Pariz" (5 p.) e "Livros Portuguezes publicados em Portugal" (2 p.). Esta classificação será adotada regularmente a partir de então. ${ }^{12}$ No Catalogo dos livros Portuguezes, Latinos, Francezes, Inglezes Paris em Casa do Vo Jean-Pierre Aillaud-Monlon, ${ }^{13}$ de 1860, é mencionado que a casa é de "Livreiros de suas Majestades o emperador do Brazil e el Rei de Portugal". As listas deste tipo se sucedem e crescem nas décadas de 1860 e 1870, ${ }^{14}$ apresentando algo entre 50 e 70 páginas, o que mostra a amplitude da oferta lusófona nessa

11 Archives de Paris, dossier D11 U3 87, faillite 6948 du 16 juillet 1831. "Este estabelecimento recebeu como capital 25000 francos de livros a 15\% de desconto somente sobre o catálogo. O ato de fundação da sociedade é de 6 de abril de 1827 e expirou a $1^{\mathrm{e}}$ de março de 1833. O comércio estando já muito asfixiado no Rio de Janeiro, a última revolução o aniquilara".

12 Notadamente em 1851. Seu endereço em Paris é então: 13, quai Voltaire.

13 A casa estava então instalada em 47, rue Saint-André-des-Arts. Esse catálogo não possui menos que 68 páginas.

14 A coleçao Q10B da Bibliothèque Nationale de France (BNF) conserva os catálogos dos anos 1863 e 1874. 
casa agora especializada nesse ramo. A casa Aillaud continua, então, sua atividade na França, paralelamente à sua instalação no Brasil.

Os Barrois, ${ }^{15}$ pai e filho - o primeiro já ativo na Revolução -, estão entre os primeiros a ocupar este segmento do mercado do livro e, mesmo publicando apenas 12 livros em português, sua coleção é interessante. Em 1811, em abril de 1816 e, depois, em fevereiro de 1817, esta casa publicou catálogos ${ }^{16}$ dedicados exclusivamente aos livros nesse idioma. Em seus catálogos gerais, regularmente colocados em circulação, tal como os de 1812 e 1820, por exemplo, aparecem sempre alguns livros em português. Bobée e Hingray, que os sucederão, também oferecerão alguns livros nessa língua.

Os Bossange, ${ }^{17}$ o pai, Martin, e seus dois filhos, Adolphe e Hector, são totalmente voltados para o trabalho de comissão internacional na sua livraria e na sua grande galeria. Sua rede cobria todo o mundo. ${ }^{18}$ Associados, nos anos 1815-1817, em Londres, com o editor Masson, os Bossange disponibilizaram a seus clientes imponentes catálogos de livros em diversas línguas. $\mathrm{O}$ de janeiro de 1815 apresenta uma lista de livros em português, ${ }^{19}$ sendo que apenas um deles havia sido publicado pelos mesmos. Em 1824, Bossange pai, instalado no número 60, da rue de Richelieu, publicou um Catalogue des livres espagnols et portugais, com 20 páginas. Entre 1830 e 1836, Hector será encarregado da edição de três livros em português e, em 1837(?), publicará um catálogo Preço corriente dos livros portuguezes da livraria de Hector Bossange et compagnie.

Os livreiros-editores Galignani, ainda que especializados em língua inglesa, não negligenciam os livros em outros idiomas, como evidenciado pelo catálogo (sd), dos anos 1833-1834, consagrado aos livros em italiano, espanhol, alemão e português. Ao longo do século XIX, a Livraria Europeia de Baudry ${ }^{20}$ se dedicará às culturas estrangeiras. Ela não apresenta catálogos específicos para os livros em português, enquanto o mesmo existe para o inglês, o italiano e o alemão, ${ }^{21}$ o que não impede que esse estabelecimento

15 BARBER, Giles. Galignani's and the publication of English books in France from 1800 to 1852. The Library, n.5, vol.XVI, p.267-286, 1961.

16 Todos os catálogos que ele menciona nesse artigo estão conservados na BNF na coleção Q10B.

17 FELKAY, Nicole. Le musee encyclopédique de Martin Bossange. Bulletin du bibliophile, p.32-39, 1984-1 e FELKAY, Nicole. La Librairie Bossange. In.: GALARNEAU, Claude e LEMIRE, Maurice. (dir.) Livre et lecture au Québec 18001850. Québec: Institut québecois de recherche sur la culture, 1988, p.43-58. Ver também GROLLEAU-FRICARD, Anthony. Le réseau Bossange dans trois récits de voyage. In: LAMONDE, Yvan e POTON, Didier. (dir.) La Capricieuse (1855): poupe et proue. Les relations France-Québec (1760-1914). Québec: Presses de l'Université Laval, 2008, p.56-57 e COOPER-RICHET, Diana. La librairie Bossange et le commerce transatlantique au début du XIX siècle. Retour sur les échanges entre "centre" et "peripherie". Communication au colloque international Passeurs d'histoires. Figures des relations France-Québec en histoire du livre, Montréal, 10-13 juin 2008.

18 COOPER-RICHET, Diana. La librairie Bossange et le commerce transatlantique au début du XIX ${ }^{\circ}$ siècle.

19 Catalogue des dépôts de livres français établis par Bossange et Masson, imprimeurs-libraires à Paris.

20 A casa Baudry, que virou Baudry Dramart, depois Dramart-Mesnil, uma das raras casas que se mantiveram ativas durante todo o século XIX no setor do livro em linguas estrangeiras, foi estudada por Jean-Benoît Francou, Baudry, un éditeur pirate du XIX ${ }^{\circ}$ siècle ou la Librairie Européenne de 1815 à 1852, dissertação de mestrado orientada por Diana Cooper-Richet e Jean-Yves Mollier, na Université de Versailles Saint-Quentin-en-Yvelines, 1999.

21 Catálogos de livros em inglês entraram em circulação em maio de 1822, e, respectivamente, em maio de 1823 , em junho de 1824; em italiano, haverá um em março 1824 
tenha tido um interesse na produção lusófona. Baudry publica pelo menos 7 livros em português. No Catalogue des principaux livres en langues étrangères qui se trouvent chez Baudry, de 1820, entre os 600 livros, juntamente com as publicações em inglês, italiano, espanhol, holandês e flamengo, estão alguns títulos em português, bem como no de 1826.

Um certo número de outros impressores-livreiros parisienses contribuiu com a circulação de livros em português, especialmente no que diz respeito à impressão. Na verdade, qualquer escritor podia contratar uma oficina de sua escolha para que seus escritos fossem ali impressos, e foi assim que algumas delas contribuíram com esse fenômeno editorial. Este é o caso da editora Pillet - a mesma que, em 1811, publicara a Bibliographie de l'Empire français, e o Journal Général de l'imprimerie et de la librairie, que se transformou, em 1814, na Bibliographie de la France, a seu cargo até 1856 - que imprimirá 35 livros em português. Didot que, ${ }^{22}$ juntamente com Panckoucke, foi uma das maiores editoras do século XVIII, se tornarão gradualmente uma única editora, notadamente adquirindo caracteres que farão sua reputação. Esta casa imprimirá sozinha 23 livros em português. Outras editoras também o farão, como Pommeret e Guénot - 19; José Tastu -13; P. N. Rougeron - 11; Rey e Gravier- $10 .{ }^{23}$ As últimas imprimiam livros em português desde 1820, ${ }^{24}$ mas também em italiano, e seus sucessores, Rey e Belhatte - Livrarias de Sua Majestade o Rei de Portugal, ${ }^{25}$ ainda estavam ativos no mesmo nicho em 1864, quando aparece o Catálogo da Livraria portugueza. Na mesma direção, J. Smith - 8;26 Renouard - 4; Charles-Joseph Hingray - 3; e Pommeret et Moreau também colocam livros em português no mercado, ainda que em medida menor. Além disso, não era raro que, a fim de limitar os riscos e partilhar os custos, os editores se associassem uns aos outros para colocar no mercado um livro em português. Este será o caso de Hingray e Baudry, de Pillet, Aillaud e Baudry, de Bobée e Rignoux, assim como de Smith, Papinot, Aillaud, Pihan e Delaforest

\section{Quais obras em português estavam disponíveis em Paris?}

Na introdução à sua lista de livros publicados em português na França, na primeira metade do século XIX, Victor Ramos analisa as diferentes fases por que passa a produção desses livros na França. ${ }^{27}$ Até meados da década

22 Sobre a maison Didot, ver : MOLLIER, Jean-Yves. L'argent et les lettres: Histoire du capitalisme d'édition (18801920), p.81-101.

23 Seus sucessores Rey e Belhatte são livreiros de Sua Majestade o Rei de Portugal.

24 O Catalogue de livres de fonds et d'assortiment, conservado na série Q 10 B da BNF, portando 154 páginas e datado de 1827, propõe obras em latim, em espanhol, em inglês e cinco páginas de obras em português. Em 1860, essa casa ainda tinha obras lusófonas em seu catálogo.

25 Em 1864, o Catalogo da Livraria portugueza de Rey et Belhatte conta com 16 páginas.

26 James Smith (1812-1847), impressor, se instalou em diferentes lugares da capital: rue de la Réunion, rue Montmartre, rue Fontaine-au-Roi.

27 RAMOS, Victor. A edição em França: 1800-1850, repertório geral dos títulos publicados e ensaio crítico, p.15-39. 
de 1830, os acontecimentos políticos em Portugal e no Brasil têm uma forte influência sobre a edição de livros. Acontece, a seguir, um retorno aos temas mais tradicionais, como a afirmação da identidade nacional; mas também e, sobretudo, a tradução de grandes obras da literatura romântica, como Alexandre Dumas, Madame Leprince de Beaumont, Florian, Marmontel, Bernardin de Saint-Pierre, Mme de Staël, Charles Nodier ou Mme de SaintVenant; ou dos autores de romances em folhetins como Paul de Kock. Mas, a passagem para o português da "literatura para jornais", ou seja, dos foIhetins, acontecerá na maior parte apenas em 1840, e a mesma partirá, em seguida, para Portugal e para o Brasil nas "caixas" dos colporteurs. ${ }^{28} \mathrm{Nem}$ Victor Hugo, ou Balzac, ou Stendhal são traduzidos nessa época. Talvez isso tenha ocorrido porque esses autores não correspondiam ao gosto dos leitores para os quais esses vendedores ambulantes se faziam de intermediários. Tal como afirmou, sucintamente, Victor Ramos, ${ }^{29}$ e como, mais recentemente, foi demonstrado pelo trabalho de Sandra Guardini Teixeira Vasconcelos, ${ }^{30}$ os autores românticos da língua inglesa estão bem representados nesse processo. Walter Scott não foi o mais traduzido de todos? Mas Harriet Beecher Stowe, Fenimore Cooper, Ann Radcliffe, assim como Matthew Gregory Lewis, Daniel Defoe ou Jonathan Swift também o foram. A obra do poeta e viajante Luis de Camões (1524-1580),, ${ }^{31}$ Os Lusíadas (1572), poema em dez cantos, narrando a viagem de Vasco da Gama em direção à Índia, aparece muito freqüente nos catálogos de livreiros parisienses especializados em livros lusófonos. De 1818 a 1832, os Bossange oferecem, sem interrupção, este livro em sua versão original, assim como, em 1825, Dondey-Dupré, 32 importante família de livreiros e editores especializados em línguas orientais, e, em 1846, Baudry. Esta epopéia de visão planetária, cheia de conhecimentos clássicos, já não se encontrava à disposição no mercado mexicano desde o final do século XVI e início do século XVII? ${ }^{33}$ Baudry propõe também, de José da Fonseca, Prosas selectas ou Escolhas dos Melhores logares dos auctores portuguezes antiguos e modernos ordenada e correcta, publicado por ele em 1837, e Les aventures de Télémaque, de Fénelon, disponível em versão bilíngüe francês-português, e, a partir de 1851, em seis idiomas diferentes.

28 RAMOS, Victor. A edição em França, p.33. NT: Colporteurs eram os vendedores ambulantes de miudezas, especialmente panfletos e livros de edição barata.

29 RAMOS, Victor. A edição em França, p.26.

30 VASCONCELOS, Sandra Guardini Teixeira. Présentation. Cahiers du Brésil Contemporain - Cheminements du roman dans le Brésil du XIXe siècle, n.69/70, p.5-10, 2008.

31 Escrito igualmente Camoës.

32 COOPER-RICHET, Diana. Paris, capitale des polyglottes? Edition et commercialisation des imprimés en langues étrangères sous la Restauration; MOLLIER, Jean-Yves. L'argent et les lettres: Histoire du capitalisme d'édition (1880-1920), p.320-321.

33 SANCHEZ, Carlos Alberto Gonzales. Los mundos del libro: medios de difusión de la cultura occidental en las Indias de los siglos XVI y XVII. Seville: Universidad de Sevilla, 2002, p.227, cité par GRUSINSKI, Serge. Les Quatre parties du monde: histoire d'une mondialisation. Paris: Editions de La Martinière, 2004, p.122. 
Dicionários e léxicos são constantes na oferta e na produção de livros em português, uma vez que eles aparecem ao longo de todo esse período, não estando ligados aos movimentos políticos que tiveram lugar no mundo lusófono. Aillaud os publica a partir de 1833, ${ }^{34}$ como Bossange e Baudry. O Nouveau dictionnaire portatif des langues françaises et portugaises, de Francisco Solana Constancio, impresso por Renouard, datado de 1828, era vendido nas livrarias Rey e Gravier, Baudry e Bobée. Podia-se igualmente ser obtido o Chrestomathie ${ }^{35}$ polyglotte en extrait des poètes grecs, italiens, espagnols, portugais, anglais, français, de M. Lebas e M. Régnier (1835), disponível em Hingray, T. Barrois, Baudry, Hachette; ou mesmo os Dialogues usuels et familiers, nouveau guide de conversation en 6 langues (1852), por Bellanger, Wittcomb, Steuer, Zirardini, Pardal e Moura; ou ainda o Nouveau guide de conversation ou dialogues usuels, entre os quais o português (1846), de Bellanger, Witcomb, Steuer, Zirardini, à venda em Baudry, Stassin e Xavier, Amyot, Truchy.

A maioria desses estabelecimentos vendia sortimento de livros publicados em outras cidades e países, principalmente em Coimbra, Lisboa e Londres. Sua seleção era então relativamente ampla. Alguns exemplos são suficientes para comprovar. No catálogo de 1824, da casa de Bossange, há mais de 20 livros publicados em Londres ou em Paris, inclusive traduções em português de Lesage e de Marmontel. Martin Bossange, bibliotecário do rei, coloca em circulação, em 1834, um Catalogue de collection d'ouvrages dans tous les dialectes de l'Europe et dans ceux de la France en particulier, à vendre en entier. Entre os tópicos desta lista, encontra-se a seção "Poetas e historiadores espanhóis e portugueses", que apresenta nada menos que 25 títulos publicados em Portugal, Coimbra e Lisboa, alguns dos quais datam do final do século XVIII - entre 1761 e 1781. Um ano mais tarde, em 1835, o Catalogue de livres en espagnol anciens et modernes portugais et limousins qui se trouvent à la Galerie de Bossange père (20 páginas) também oferece uma seleção de livros lusófonos publicados em Londres, assim como em Lisboa, incluindo um trabalho de 1745. Na Maison de commission pour l'étranger de H [Ector] B [Ossang] e cia., o catálogo de 1838 apresenta 3 livros em português, todos publicados em Paris. Nos números 4 e 5 de seu Bulletin bibliographique ou liste des ouvrages nouveaux publiés en France, de 15 de julho de 1830, aparece a publicação dos Annaes, ${ }^{36}$ do historiador grego Corneho Tacito, traduzido em português, oferecido à sua pátria e aos amigos pelo jornalista e político liberal português José Liberato Freire de Carvalho. ${ }^{37}$ Este catálogo inclui uma seção dedicada ao português.

34 Em abril 1833, o catálogo conta com 26 páginas, das quais apenas uma de livros em português.

35 Do grego krestos: antologia de textos antigos de autores clássicos, notadamente utilizados para o aprendizado de uma língua estrangeira.

36 Ab Excessu diui Augusti, texto conhecido sob o nome de Annales.

37 Exilado em Londres, ele foi editor de um jornal em português nessa cidade. 
Se, como vimos, Jean-Pierre Aillaud publica mais de 50 livros em português, entre 1797 e 1850, ele coloca a venda muitos outros, especialmente na segunda metade do século, durante a qual parece se especializar ainda mais nesse setor lingüístico. Em 1820, o Suplemento ao Catálogo menciona cerca de vinte livros em português, dos quais alguns publicados em Portugal. Em 1821 e em 1826, ele apresenta 6 títulos lusófonos, incluindo 2 vindos de Lisboa. Seis anos depois, a oferta aumentou consideravelmente, uma trintena de títulos vindos de Londres e Portugal está disponível, dos quais uma grande parte são os dicionários.

Quantos livros em português circularam, na França e a partir da França, durante a primeira metade do século XIX? Se se supõe, como é legitimo supor, que foram feitos, em média, 500 exemplares de cada livro publicado na capital, estima-se que durante esse período, quase 300.000 livros em português foram impressos em Paris. Se acrescentarmos a esse sortimento os livros oferecidos pelas livrarias em seus catálogos, é provável que, pelo menos, 350.000 livros em português foram colocados em circulação. A presença lusófona não pára por aí, periódicos e os passeurs culturais que se envolveram na sua produção também são numerosos na capital francesa.

\section{Periódicos em português e passeurs de cultura lusófona}

O século XIX, se é o século da explosão do mundo editorial, ele é também, de acordo com certo número de historiadores, o "século do jornal" ou o da "civilização do jornal". A efervescência inesperada da imprensa lusófona na capital francesa foi testemunha da vontade de alguns passeurs de cultura - livreiros-editores, homens de letras, cientistas franceses, portugueses ou brasileiros - de fazer ouvir, através dos meios de comunicação mais modernos, a voz do mundo lusófono, de circular suas idéias, mas também de ajudar a divulgar os avanços na ciência e as Luzes do pensamento europeu.

\section{Periódicos em português publicados em Paris}

Pode parecer surpreendente, uma vez que sua existência é pouco conhecida, descobrir que entre as muitas publicações em línguas estrangeiras disponíveis no mercado, em Paris, ${ }^{38}$ entre os anos 1815 - data da queda do Primeiro Império na França - e o fim dos anos 1830, encontram-se nada menos que dez periódicos ou revistas impressos em português, além de

38 No último número de abril de 1815 de O Observador Lusitano em Pariz, p.652-653, está indicado que já existem periódicos portugueses em Londres. 
quatro títulos que foram apenas anunciados. ${ }^{39}$ Se esses periódicos são bastantes diferentes uns dos outros, eles têm, no entanto, certo número de características comuns, entre os quais, em primeiro lugar, sua precariedade. Muito efêmeros, não duram mais que um a quatro números, com exceção de um deles. Sérios, na sua maior parte, são dominados pelas visões científicas e culturais, inclusive políticas, de seus promotores, bem como pela sua ambição de contribuir para o progresso da jovem nação brasileira em formação.

Entre os dez periódicos que realmente "viram o dia", quatro foram concebidos e dirigidos por Francisco Solano Constancio. A primeira destas publicações é O Observador lusitano em Pariz ou collecçao literaria, politica e commercial - 4 números entre janeiro e abril de 1815, tendo alguns atingido 660 páginas. Em seguida aparece os Annaes das Sciencias, das Artes e das letras por huma Sociedade de Portuguez residente em Pariz. Foi anunciado pela primeira vez, em 17 de Junho de 1818, na Bibliographie de la France, por meio de um prospecto intitulado Prospecto de huma nova obra periodica intitulada, os Annaes das Sciencias... Tratava-se de um periódico fundado em julho de 1818 e que desaparecerá em abril de 1822, logo após a publicação do volume XVI. Foi substituído, em 1827, pelos Novos Annaes das Sciencias e das Artes dedicados as que fallem a lingua portugueza em ambos os hemispherios, que teve tiragem de apenas 4 números. Finalmente, em janeiro de 1837, Constancio irá produzir uma única tiragem do Archivo dos Conhecimentos úteis, periódico mensal destinado a promover a agricultura e indústria de Portugal e do Brasil, publicado por Jean-Pierre Aillaud. É interessante notar que, se o primeiro destes periódicos está presente nas coleções da Bibliothèque Nationale de France, é graças à doação feita pelo abade Grégoire, sacerdote revolucionário e antiimperialista, a quem Constancio cuidadosamente enviou cópias de sua publicação. Esse cuidado testemunha a orientação progressista das opiniões de seu criador e, ao mesmo tempo, sua admiração por aquele que soube rejeitar o Império.

Apesar das dificuldades que parecem ter atingido Constancio, ele parece querer colocar, a qualquer custo, uma publicação lusófona no mercado parisiense. Na "Advertência" 40 da última edição dos Annaes..., datada de abril de 1815, observou que as ligações marítimas entre a França e Portugal estavam suspensas, devido ao regresso de Napoleão à França durante os Cem Dias e, como a censura portuguesa havia distorcido o conteúdo do seu jornal, ele informou que se decidira por suspender sua publicação. Sem dúvida, encontrou outros obstáculos enquanto tentava criar seu terceiro revista, Novos Annaes..., e também, dez anos mais tarde, com o último Archivo de conhencimentos..., já que todas elas desapareceram rapidamente.

39 Assim, a cada dois anos, entre 1815 e 1837, é lançado em média um título em português na capital francesa. 40 Annaes das Sciencias, das Artes e das letras por huma Sociedade de Portuguez residente em Pariz, p.652-653. 
Apenas a segunda de suas tentativas, a dos Annaes..., foi coroada com um êxito, ainda que pouco duradouro.

Como eram resultantes do trabalho de uma única pessoa, esses periódicos apresentam naturalmente certo número de pontos comuns, principalmente a abordagem científica e enciclopedística do conhecimento, mesmo se as ciências "duras" parecem ter sido privilegiadas pelo seu redator-chefe, médico de formação. Nos primeiros tempos, uma certa vontade de valorizar o mundo lusófono - Portugal e o Brasil após 1822 - é clara e parece bastante evidente, bem como a vontade de promover o iluminismo e o progresso, inclusive na esfera política, com artigos sobre política imperial e a abolição da escravatura. A literatura também está presente, tanto a francesa - como, em particular, os comentários sobre Les Martyrs (1809), de Chateaubriand -, mas também a portuguesa.

Entre os outros seis periódicos em português que foram lançados durante esse período, apenas um tentou competir intelectualmente com os precedentes. O redator-chefe do periódico mensal, O Contemporaneo politico e literario (3 números em 1820), ${ }^{41}$ culpou os Annaes... de ter conscientemente excluído os estudos literários de suas páginas. Ele disse querer, por sua vez, dar-lhes um lugar importante, tanto em português quanto em outras línguas. Em destaque, o periódico imprimiu, inclusive, quatro versos de Camões. No entanto, são as observações sobre a vida política que se tornaram o centro das preocupações desta nova publicação, que se mira nos exemplos europeus, franceses e ingleses, para observar o funcionamento da monarquia constitucional.

A Abelha ou Collecçao de conhecimentos os mais agradaveis, instructivos, necesarios e uteis as classes da sociedade, extrahidos dos jornaes scientificos e literarios de toda a Europa e dos obras dos melhores escriptores . Jornal portugués dirigido e publicado mensalmente em Pariz (1 número em 1830) é o trabalho de Francisco Ladislas Alvares d'Andrada. Esta publicação mensal de tipo enciclopedístico tirava a maior parte de seu conteúdo de outros periódicos e revistas europeus. Ela utilizava a técnica de cortar e colar, desde então amplamente empregada no mundo da imprensa naquele momento. A Abelha... pretendia realizar uma "obra moral", contribuindo para a "felicidade dos povos", mas, acima de tudo, constituir-se como eco da civilização européia para os lusófonos do mundo inteiro. Como as publicações de Constâncio, esta revista era destinada a partir regularmente para Portugal e para o Brasil, como mostram as coleções da Biblioteca Nacional de Portugal, em Lisboa, e as da Fundação Biblioteca Nacional e do Real Gabinete Português de Leitura, no Rio de Janeiro. ${ }^{42}$

41100 páginas para a primeira edição.

42 A primeira das três conserva, em suas coleções, O Observador..., les Annaes..., O Contemporaneo..., os Novos Annaes...e O Padre.... A segunda propõe igualmente O Observador.... e os Novos Annaes.... Enfim, o gabinete de 
O caso d'O Patriota Brasileiro, um único número em 1830, publicado pela Livraria dos Estrangeiros de Renouard, é interessante porque, no próprio título, o periódico se coloca, mesmo oito anos após a independência, em defesa da jovem nação brasileira. Tal como seus antecessores, o periódico é dedicado ao país que o acolhe, a França, terra do iluminismo e do conhecimento. Quase exclusivamente, o conteúdo do único exemplar conservado nas coleções da BNF é dedicado aos artigos históricos, aos textos que versam sobre a nova Constituição outorgada por dom Pedro I, às informações científicas, políticas e literárias do Brasil.

A única revista que parece ter marcado a história intelectual do Brasil é Nitheroy. Revista Brasiliense, sciencias, lettras e artes (2 volumes, em 1836), ${ }^{43}$ cujo lema era "Tudo pelo Brasil e para o Brasil". Aqui estão novamente as Luzes da civilização, apresentadas de forma a que beneficiem os brasileiros. Seus colaboradores, dos quais o principal era Domingos José Gonçalves de Magalhães, são conhecidos por terem contribuído largamente para a introdução do romantismo no país.

Por último, devem ser mencionados dois outros títulos de periódicos muito particulares. Primeiro, uma pequena publicação intitulada $O$ Padre Malagrida ou a Tezeira periodico politico e literario (1 ou 2 números em 1829), cujo título deriva do nome de um jesuíta de origem italiana que partiu para o Brasil no início do século XVIII e que foi queimado publicamente em Lisboa pela inquisição por ter alegadamente participado de uma conspiração contra o rei. ${ }^{44} \mathrm{O}$ outro periódico é um folhetim especializado no cultivo da vinha, intitulado $O$ Vinhateiro. Obra em que se tratarà de cultura da vinha, da fabricaçao e conservaçao de vinho, da distillaçao dos agoas aredentes $\square$ (um número em 1832), que não se compreende muito bem a sua presença em Paris. Por último, devemos mencionar também os quatro periódicos anunciados com os seguintes nomes como descritos adiante, um em 1826, 0 Nivelador, Jornal scientifico, techino e literario redigico por huma sociedad de Portuguez rezidentes em Paris; ${ }^{45}$ os outros três em 1832: O Independente, O Pergumentador, O Tribuno do Povo, ${ }^{46}$ todos os títulos significativos apontando suas ambições abrangentes. Estes três últimos periódicos nunca chegaram à luz do dia, mas testemunham o vigor da imprensa da época, mesmo a de língua estrangeira.

leitura portuguesa do Rio tem, como as duas outras O Observador ...., e como a biblioteca de Lisboa os Annaes...e O Padre. Ele é o único que podia oferecer Nitheroy para leitura.

43 BAREL, Ana Beatriz Demarchi. (org.) Revista Nitheroy, Edição fac-similar acompanhada de textos críticos, Coimbra, Minerva, 2006.

44 VOLTAIRE. Euvres complètes. Paris: Crapelet, 1819, tome XXIX; VOLTAIRE. Philosophie. Paris: Renouard, 1819, tome I, p.403. É em um sermão hebreu pronunciado pelo Rabino Akib, em Smyrne, no dia 20 de novembro de 1761, ano da morte do pai Gabriel Malagrida, que é aqui citado. O subtítulo do periódico evoca tesouras, sem dúvida em referência à censura.

45 Bibliographie de la France, 14 de junho de 1826.

46 Esses quatro títulos foram dados por CANTO, Ernesto de. Ensaio bibliográfico. Punta Delgada: Tipografia de Arquivos dos Açores, 1888, p.287, 291 e 293. 
A voz do mundo lusófono fez-se escutada a partir de Paris, por meio da imprensa periódica. Neste esforço de propagação do iluminismo, da França para Portugal e o Brasil, participaram certo número de passeurs, homens do livro e intelectuais, franceses, portugueses e brasileiros.

\section{Passeurs da cultura lusófona}

Rey e Gravier, Bobée, Firmin Didot, Renouard, todas essas instituições contribuíram, quer com Constâncio, quer com Alvares d'Andrada, quer com alguns outros, ajudando-os a produzir e distribuir suas revistas e periódicos em português para os lusófonos em Paris, mas especialmente aos residentes em Portugal e no Brasil, a quem eles queriam mostrar a evolução da vida política e intelectual européia. O trabalho de Antoine-Augustin Renouard ${ }^{47}$ e seu filho Paul, impressor com uma grande variedade de caracteres - 0 que não irá impedir os diretores de periódicos lusófonos de se queixarem da falta de caracteres disponíveis em Paris ${ }^{48}$-, bem como o trabalho realizado pela casa Firmin Didot ${ }^{49}$ são parcialmente conhecidos. No entanto, é incerta a maneira como participaram outras livrarias listadas, das quais as informações são parciais, principalmente no que diz respeito as suas atividades no exterior.

Um grande número de obras, mas igualmente de periódicos em línguas estrangeiras podiam ser lidos, sob assinatura, nos gabinetes de leitura especializados. A Livraria dos Estrangeiros, francesa, inglesa e americana, dos Renouard, por exemplo, situada no número 55, rue Neuve Saint Augustin, dispunha em seus

salões literários, espaçosos e magníficos (...) todos os jornais da França, Irlanda, Escócia, América, e também aqueles que aparecem na Itália, Alemanha, Portugal, Holanda... Está escrito no seu prospecto de 1831, que possui, todos os jornais e periódicos, de obras literárias e científicas, publicados em ambos os mundos..$^{50}$

Sem dúvida podia-se ler nesse estabelecimento os diversos periódicos publicados em português em Paris, ${ }^{51}$ em especial O Patriota Brasileiro. Periodico mensal, cujo único volume foi publicado pela mesma Livraria dos Estrangeiros. Mas será que os passeurs lusófonos se encontravam lá para ler os jornais de seu país de origem?

47 COOPER-RICHET, Diana. La redécouverte des éditions aldines au XIX ${ }^{\circ}$ siècle: Antoine-Augustin Renouard, bibliophile, collectionneur et passeur culturel. In: PORTEBOIS, Yannick et TERPSTRA, Nicholas. (éd.) The Renaissance in the nineteenth century. Le XIX siècle renaissant. Toronto: Center for Reformation and Renaissance Studies, 2003, p.179-197.

48 A Abelha..., n.1, p.60

49 MOLLIER, Jean-Yves. L'argent et les lettres: Histoire du capitalisme d'édition (1880-1920), p.81-101.

50 Catalogue des livres français qui se trouvent en lecture à la libraire des Etrangers. Paris, 1831.

51 RAMOS, Victor. A edição em França, p.151. 
As guerras napoleônicas, a turbulência política no mundo lusófono, a guerra civil em Portugal, seguida por problemas políticos persistentes nesse país eram causas de movimentos populacionais, ocorridos em diferentes ondas durante esse período, e que explicam a presença de emigrantes políticos portugueses em Paris. Estes possuíam um nível cultural elevado, eram liberais, anti-clericais e anti-absolutistas, além de leitores dos enciclopedistas, de Voltaire, de Rousseau e de Montesquieu, como também adeptos dos princípios educacionais desenvolvidos por Fénelon, em Télémaque. Vieram se refugiar na França, onde poderiam ser escutados, tornando-se, assim, passeurs da cultura lusófona no restante mundo.

Alguns nomes desses passeurs deste período devem ser lembrados: Francisco Solano Constancio, Francisco Ladislau Alvares d'Andrada, Domingos José Gonçalves de Magalhães, Manuel José Araújo Porto-Alegre e Sylvestre Pinheiro Ferreira. Foi o primeiro deles o mais ativo na produção de periódicos em português. Filho do então cirurgião do rei de Portugal, Francisco Solano Constancio (1777-1846) era também médico mas, acima de tudo, foi diplomata à serviço de Portugal, primeiro em Paris e, em seguida, em Washington, onde foi nomeado embaixador. Ele renunciou ao cargo, em 1829, para então retornar definitivamente a Paris, onde dividiu seu tempo com a escrita. Ele é, por exemplo, o editor da publicação mensal intitulada Esprit des revues anglaises. Analyse critique des revues trimestrielle d'Edimbourg et de Londres (julho de 1841-fevereiro 1842), no qual analisa, mês a mês, com um espírito crítico e aberto, todos os assuntos abordados pelos periódicos britânicos. Ele é também um tradutor ativo. Sua tradução de Des Principes de l'économie politique et de l'impôt (1817), de Ricardo, editado por Jean-Pierre Aillaud, em 1819, ainda é consultada hoje em dia. É também o autor de uma Nouvelle grammaire portugaise à l'usage des Français, publicada, em 1832, pela mesma editora. Constancio representa um caso exemplar de passeurs de cultura entre o mundo lusófono, a França e a Inglaterra.

Sobre Francisco Ladislau Alvares d'Andrada, promotor, em 1830, da revista Abelha..., que se dizia querer competir com os periódicos de Constancio, os dados biográficos são escassos. No entanto, o retrato que se desenha dele, por meio das coleções da BNF, mostra um tradutor ativo do francês e inglês para o português. Entre as traduções que realizou incluemse os romances de Alexandre Dumas, como A condessa de Charny, em 1854, publicada por Cadot; mas também as obras de Benjamin Franklin, 52 impressas em Londres, em 1832; ou ainda La cabane de l'Oncle Tom ou la vie des nègres en Amérique, de Harriet Beecher Stowe, publicada por Rey e Belhatte, em 1853. Notamos ainda que ele próprio é o autor de vários livros,

52 Londres: Greenslaw. 
incluindo História de José de Faro ou o mercador ambulante..., ${ }^{53}$ e também uma história da Guerra da Crimeia: A Russia, a Turquia et a historia da actual guerra de Oriente. ${ }^{54}$ Andrada aparece então, na sua vontade de colocar no mercado uma revista intelectual e transcultural, como um verdadeiro mediador, como um observador da evolução e dos progressos do mundo, do qual ele quer dar seu testemunho no mundo lusófono.

Médico e escritor como seu pai, Domingos José Gonçalves de MagaIhães (1811-1882) é considerado o introdutor do romantismo no Brasil. Em 1836, quando vivia em Paris, aos 25 anos de idade, a publicação simultânea de Suspiros poeticos e saudades ${ }^{55}$ e da revista Nitheroy torna-se a fonte dessa reputação, embora muitos dos críticos considerem-no, apesar de tudo, um poeta medíocre. Parece-me que, se esta revista tem, ainda hoje, uma presença na história da literatura brasileira, é menos por causa da própria revista, que publicou apenas dois números fora do Brasil, do que por causa do artigo de Magalhães, intitulado "Essai sur l'histoire de la littérature brésilienne" ${ }^{56}$ Este último, também publicado em forma de livro, é considerado um manifesto a favor do romantismo, uma corrente literária então ainda pouco conhecida pelos brasileiros.

Para publicar Nitheroy, Magalhães se associou, em Paris, a Manuel José de Araújo (1806-1879), mais conhecido como pintor e professor de artes plásticas sob o nome de Araújo Porto-Alegre. No Rio de Janeiro, esse último trabalhara sob a direção de Jean-Baptiste Debret, com quem partiu para a França, em 1831. Em Paris, freqüentava os círculos românticos, onde conheceu Magalhães. Os dois, juntamente com Francisco de Salles Torres Homem (1812-1876), decidem então fundar uma revista em português: Nitheroy. Os três participavam de atividades no l'Institut Historique de Paris, ${ }^{57}$ onde o Journal publica um artigo de Araújo sobre as "Les beaux-arts au Brésil", ${ }^{58}$ mas também relata, em detalhes, o lançamento de Nitheroy, indicando que ela obteve um grande sucesso e que todos os exemplares da primeira edição foram vendidos. ${ }^{59}$

Podemos acrescentar a esses nomes o de Silvestre Pinheiro Ferreira, nascido em Lisboa, em 1769. Muito cedo entrou nos oratorianos, e, em 1797, teve que se refugiar na Inglaterra devido à sua posição liberal. Por

53 Londres: Bingham, 1832

54 Paris: Pommeret et Moreau, 1854.

55 Esse texto é tirado do segundo número da revista Nitheroy, publicado no Rio de Janeiro em J.P. Veiga em 1836

56 Nitheroy, v.l, n.1, 1836.

57 Fundado em 1833, ele tem como objetivo promover os estudos históricos. O Instituto tem como presidente Michaud, membro da Academia francesa e da Academia das Inscrições e Belas-Letras e como secretário perpétuo, Eugène Garay de Monglave (1796-1878), autor de uma Histoire de Paris, (Paris: Biblioteca popular ou a educação colocada ao alcance de todas as classes e de todas as inteligências, 1833) e de muitas outras obras.

58 Notice de Manuel José de Araùjo Porto-Alegre. In: Encyclopédia Itau Cultural arts visuels, http://www.itaucultural. org.br/aplicExternas/enciclopedia ic/index.

59 Relatório lido na $2^{\circ}$ classe do Instituto Histórico por Eugène de Monglave membro do Instituto Royal de Naples, Journal de l'Institut historique, v.3, $2^{\circ}$ ano, 1836, p.209-211. 
um tempo secretário do embaixador de Portugal, em Paris, antes de ser ele próprio encarregado, de 1802 a 1807, dos negócios diplomáticos em Berlim, uma posição que teve que abandonar por ordem de Napoleão. Juntou-se em seguida à família real no Brasil, onde ocupou cargos importantes e foi defensor da libertação dos escravos e do estabelecimento de um governo representativo, tanto na metrópole, quanto na colônia. Em 1822, acompanhou o regresso do rei dom João à Portugal e deixou o país somente após a abolição da monarquia, em abril de 1824. A partir de então, se instala em Paris, durante os 10 anos seguintes, onde escreveu livros de Direito, alguns dos quais foram colocados à venda na Bossange. Foi admitido na Académie des Sciences Morales et Politiques, seção de legislação.

\section{Conclusão}

Se, nesta primeira metade do século XIX, nenhum livreiro-editor parisiense se restringe exclusivamente à impressão lusófona, muitas casas dedicaram uma parte mais ou menos significativa de suas atividades a esse setor. A quantidade de obras produzidas, ainda que não sejam colossais, testemunham, no entanto, o papel desempenhado por Paris como um lugar de múltiplas transferências culturais, uma cidade da qual partem para o Novo Mundo impressos de todos os tipos, inclusive em português. Por meio deles circulam modelos, idéias, correntes de pensamento e novos gêneros literários.

$\mathrm{Na}$ França, alguns mediadores portugueses e brasileiros se voltaram para a produção de revistas e periódicos intelectuais e críticos - um tipo de mídia moderna, inventada na Escócia, em 1802. Eles são os observadores - encarregados de passar para o outro lado do Atlântico, para a jovem nação brasileira, mas também para Portugal, os ideais de uma monarquia constitucional, o "iluminismo" e os avanços científicos do Velho Mundo, especialmente os franceses. Graças ao trabalho de tradução de certo número deles, as produções intelectuais mais recentes, tais como as obras de economia política de Ricardo, mas também os romances franceses e ingleses, vão cruzar os mares, na língua de Camões e de Garrett, unindo os novos leitores destes países e influenciando suas elites de forma duradoura. 